Article

\title{
Platinum Nanoparticles Decrease Reactive Oxygen Species and Modulate Gene Expression without Alteration of Immune Responses in THP-1 Monocytes
}

\author{
Francesca Gatto ${ }^{1}$ (1), Mauro Moglianetti ${ }^{1,2}$, Pier Paolo Pompa ${ }^{1,2}$ and Giuseppe Bardi $1, *$ (i) \\ 1 Istituto Italiano di Tecnologia, Nanobiointeractions \& Nanodiagnostics, Via Morego 30, 16163 Genova, Italy; \\ francesca.gatto@iit.it (F.G.); mauro.moglianetti@iit.it (M.M.); pierpaolo.pompa@iit.it (P.P.P.) \\ 2 Istituto Italiano di Tecnologia, Nanobiointeractions \& Nanodiagnostics, Center for Bio-Molecular \\ Nanotechnologies, Via Barsanti Arnesano, 73010 Lecce, Italy \\ * Correspondence: giuseppe.bardi@iit.it; Tel.: +39-010-7178-1519
}

Received: 16 May 2018; Accepted: 30 May 2018; Published: 1 June 2018

\begin{abstract}
Platinum nanoparticles (PtNPs) attract great attention due to their efficient catalysis and good degree of cytocompatibility, but information about their effects on the human immune system is still missing. Monocytes are key cells of the innate immune system and the understanding of their reactions to PtNPs is crucial in view of any feasible application to human pathologies. Here, we evaluate the internalization of citrate-coated PtNPs into THP- 1 monocytes and its consequences on immune cell responses. We found that the presence of intracellular PtNPs efficiently reduce reactive oxygen species (ROS) without affecting cell viability. The physiological expression of the immune receptors Cluster of Differentiation 14 (CD14), CD11b, CC-Chemokine Receptor 2 (CCR2) and CCR5 and the expression of cytokines and chemokines are not compromised by the presence of PtNPs within THP-1 cells. On the other hand, the treatment with PtNPs modulates the transcription of sixty genes, some of them involved in lipopolysaccharide (LPS) signaling in different cells. However, the treatment with PtNPs of monocytes does not compromise the LPS-induced increase of cytokines in THP-1 monocytes in vitro. Our results demonstrate that citrate-coated PtNPs are non-toxic, perform efficient intracellular reactive oxygen species (ROS) scavenging activity and possess good immune-compatibility, suggesting them as feasible synthetic enzymes for applications in nanomedicine.
\end{abstract}

Keywords: platinum nanoparticles; monocytes; cytokines; chemokine receptors; inflammation

\section{Introduction}

The intrinsic catalytic activity of platinum nanoparticles (PtNPs), as well as other nanomaterials such as fullerenes, palladium and cerium-oxide nanoparticles (NPs), allows efficient reactive oxygen species (ROS) removing inside cells [1-3]. Several results demonstrate that PtNPs are promising candidates to develop synthetic enzymes (nanozymes) for applications in health sciences [4-13]. Pristine PtNPs or PtNPs coated with biocompatible materials have shown good cytocompatibility, although some conflicting results are present in literature [14]. The particle physicochemical properties like surface chemistry, size and shape regulate their biological fate and eventually their potential toxicity [15]. The absence of contaminants (e.g., endotoxin, Pt precursors, toxic unreacted reagents, organic solvents, etc.) during their synthesis process is a crucial point to produce biocompatible colloidal suspensions for medical aims [16]. All these parameters influence the NP delivery and its toxicological profile, often triggering unexpected immune reactions and, hence, increasing the contradiction of some results. 
The response of the immune system to PtNPs is poorly investigated. The available data describe an anti-inflammatory activity of PtNPs in murine macrophages previously stimulated with LPS [17]. Blood circulating monocytes, which are the precursors of tissue patrolling macrophages, are key cells of the innate immune system able to discriminate between "self" and "non-self" molecules [18], and aberrantly activated in acute and chronic inflammatory pathologies [19]. At the site of inflammation, cell-to-cell signals, like chemokines (chemo-attractant cytokines), mediate rapid monocyte mobilization binding their cognate receptors on the membrane and contributing to their differentiation into macrophages or dendritic cells that actively phagocytize "non-self" bodies. Furthermore, monocytes regulate growth and differentiation of the other immune cells through the release of specific cytokines, to tailor immune responses against the diverse pathogens [19]. Then, the innate immune reaction to any foreign substance, including PtNPs, is a fundamental step to be assessed in order to validate its biocompatibility. Here we show the interaction and the response of THP-1 monocytes to monodispersed 5 and $20 \mathrm{~nm}$ citrate-coated PtNPs. We did not find any PtNP-induced toxicity, despite the evident NP internalization within the cells. Interestingly, we observed PtNP-mediated ROS reduction and discovered their ability to modulate gene transcription without alteration of inflammatory cytokine release. In particular, we demonstrated very low impact of PtNPs on the immune-physiological response and following LPS-mediated monocyte activation.

\section{Materials and Methods}

\subsection{Platinum Nanoparticles Synthesis and Characterization}

Citrate-capped PtNPs were synthetized avoiding potentially dangerous contaminants during the synthetic procedure and characterized by transmission electron microscopy (TEM) using a Jeol JEM 1011 (Jeol, Akishima-shi, Japan) as previously described [9]. Limulus test (Lonza, Basel, Switzerland) was performed to guarantee NP batches being endotoxin-free. PtNPs were analyzed and the size distribution was determined measuring the diameter of at least 500 NPs.

\subsection{Cell Culture}

THP-1 cells (ATCC, Manassas, VA, USA) were grown in RPMI-1640 (Thermo Fisher Scientific, Waltham, MA, USA) supplemented with 10\% FBS (Thermo Fisher Scientific, Waltham, MA, USA), 1\% Penicillin-Streptomycin (Sigma-Aldrich, Saint Louis, MO, USA) and $0.05 \mathrm{mM}$ 2-mercaptoethanol (Thermo Fisher Scientific, Waltham, MA, USA) in a $\% \mathrm{CO}_{2}$ humidified atmosphere at $37^{\circ} \mathrm{C}$.

\subsection{Transmission Electron Microscopy (TEM) Analysis of Cellular Internalization of PtNPs}

THP-1 cells were incubated with $50 \mu \mathrm{g} / \mathrm{mL}$ PtNPs for $24 \mathrm{~h}$ and washed twice with RPMI and fixed for $45 \mathrm{~min}$ in a fixative solution ( $2 \%$ Glutaraldehyde in complete culture medium). The samples were centrifuged and the pellet fixed again with 1.5\% Glutaraldehyde solution in Na-Cacodylate buffer $0.1 \mathrm{M}$. A final post-fixation $(2 \mathrm{~h})$ in $1 \% \mathrm{OsO}_{4}$ solution in Na-Cacodylate buffer $0.1 \mathrm{M}$ was performed. The fixed samples were stained overnight in a $1 \%$ Uranyl acetate aqueous solution at $4{ }^{\circ} \mathrm{C}$. After several washes in water, samples were completely dehydrated with a scale of Ethanol, transferred in Propylene Oxide and finally infiltrated with epoxy Spurr ${ }^{\mathrm{TM}}$ (SPI-Chem) resin. Once the resin has hardened for $48 \mathrm{~h}$ in oven at $65^{\circ} \mathrm{C}, 70 \mathrm{~nm}$ thick sections were cut with a Leica EM UC6 ultra-microtome. TEM images were collected with a Jeol JEM 1011 (Jeol, Akishima-shi, Japan) electron microscope (Electron Microscopy Facility-Fondazione Istituto Italiano di Tecnologia, Via Morego 30, 16163 Genova), operating at an acceleration voltage of $100 \mathrm{kV}$, and recorded with an $11 \mathrm{Mp}$ fiber optical charge-coupled device (CCD) camera (Gatan Orius SC-1000).

\subsection{Intracellular Uptake of Pt NPs by Flow Cytometry Analysis}

THP- 1 cells $\left(5 \times 10^{5}\right.$ cells $/ \mathrm{mL}$, 12-well plates) were incubated with $50 \mu \mathrm{g} / \mathrm{mL}$ of the appropriate PtNPs. After 2, 6 and $24 \mathrm{~h}$ incubation, the cells were washed and resuspended in Phosphate 
Buffered Saline (PBS) (Lonza, Basel, Switzerland) for the flow cytometry analysis. The effect of PtNPs internalization on cellular side scatter was evaluated by flow cytometry with MACSQuant Analyzer (Miltenyi Biotec, Bergish, Germany) using MACSQuantify software (Miltenyi Biotec, Bergish, Germany).

\subsection{Annexin-PI Assay}

Cell viability was quantified by using Annexin V-PI assay (Miltenyi Biotec, Bergish, Germany) according to the manufacturer's instructions. In brief, the cells $\left(5 \times 10^{5}\right.$ cells $/ \mathrm{mL}$, 12-well plates) were incubated with $50 \mu \mathrm{g} / \mathrm{mL}$ of the proper PtNPs for 2,6 and $24 \mathrm{~h}$. After the treatments, the cells were washed with $1 \times$ Binding Buffer at $300 \times g$ for $10 \mathrm{~min}$, resuspended in $1 \times$ Binding Buffer and incubated with Annexin V-FITC for $15 \mathrm{~min}$ in the dark at room temperature. Subsequently, the cells were washed adding $1 \times$ Binding Buffer, centrifuged at $300 \times g$ for $10 \mathrm{~min}$ and then resuspended in $1 \times$ Binding Buffer. Propidium Iodide (PI) solution was added immediately prior to analysis by flow cytometry with MACSQuant Analyzer (Miltenyi Biotec, Bergish, Germany). The percentage of viable, necrotic or apoptotic cells was evaluated using MACSQuantify software (Miltenyi Biotec, Bergish, Germany). $10 \%$ DMSO was used as positive control.

\subsection{WST-8 Assay}

Cell metabolic activity was determined using a WST-8 (2-(2-methoxy-4-nitrophenyl)-3-(4-nitrophenyl)5-(2,4-disulfophenyl)-2H-tetrazolium, monosodium salt) assay (Sigma-Aldrich, Saint Luis, MO, USA) following the manufacturer's instructions. Briefly, after 2, 6 and $24 \mathrm{~h}$ incubation with PtNPs at the proper concentration the cells were washed twice, resuspended in complete culture medium and seeded in 96-well plates a density of 50,000 cells $/ 100 \mu \mathrm{L}$. $10 \mu \mathrm{L}$ of Cell Counting Reagent WST- 8 were added to each well and the plates were incubated in a $5 \% \mathrm{CO}_{2}$ humidified atmosphere at $37^{\circ} \mathrm{C}$ for $2 \mathrm{~h}$. The orange WST- 8 formazan product was measured on a Synergy HT (Biotek, Winooski, VT, USA) microplate reader at a wavelength of $460 \mathrm{~nm} .10 \%$ DMSO was used as positive control.

\subsection{Receptor Expression}

The cells $\left(5 \times 10^{5}\right.$ cells $\left./ \mathrm{mL}\right)$ were incubated with $50 \mu \mathrm{g} / \mathrm{mL}$ Pt-NPs for 2, 6 and $24 \mathrm{~h}$. After incubation, the cells were washed with RPMI at $300 \times \mathrm{g}$ for $5 \mathrm{~min}$, resuspended in RPMI/0.5\% Bovine Serum Albumin (BSA) (Miltenyi Biotec, Bergish, Germany), and incubated with fluorescently labelled antibodies (FITC-conjugated mouse anti-human CD195 (CCR5), Alexa Fluor 647-conjugated mouse anti-human CD192 (CCR2), BD Pharmigen; VioBlue-conjugated mouse anti-human CD14, PE-conjugated mouse anti-human CD11b, Miltenyi Biotec) at the manufacturer's recommended concentration for $15 \mathrm{~min}$ on ice in the dark. The cells were then washed and resuspended in RPMI. Cell-associated fluorescence was analyzed by flow cytometry with MACSQuant Analyzer, gating the living cells based on light forward scattering (FSC) and side scattering (SSC). 100,000 events per sample were acquired.

\subsection{Inflammatory Cytokine Release}

THP- 1 cells were incubated with $50 \mu \mathrm{g} / \mathrm{mL}$ PtNPs for $6 \mathrm{~h}$, then washed twice and reseeded in fresh medium. IL-1 $\beta$, IL-8, MCP-1, MIP- $1 \beta$, RANTES and TNF- $\alpha$ release were evaluated after $24 \mathrm{~h}$ with a Bio-Plex MAGPIX Multiplex Reader (Bio-Rad, Hercules, CA, USA) according to the manufacturer's instructions.

The same experiment has been performed with LPS-stimulated THP- 1 for $24 \mathrm{~h}$ after $6 \mathrm{~h}$ administration of $50 \mu \mathrm{g} / \mathrm{mL}$ PtNPs. $100 \mathrm{ng} / \mathrm{m}$ LPS have been used as positive control.

\subsection{DCFDH-DA Assay}

THP-1 cells were cultured at a density of $5 \times 10^{5}$ cells $/ \mathrm{mL}$ in 12-well plates in presence of $50 \mu \mathrm{g} / \mathrm{mL}$ PtNPs for $6 \mathrm{~h}$. The cells were washed with sterile PBS and incubated with $5 \mu \mathrm{M}$ DCFH-DA 
$\left(2^{\prime}, 7^{\prime}\right.$-dichlorofluorescein diacetate, Molecular Probes) in PBS for 10 min at $37^{\circ} \mathrm{C}$. The cells were then washed with PBS and the DCF fluorescence intensity was measured with MACSQuant Analyzer (Miltenyi Biotec, Bergish, Germany). $1 \mathrm{mM} \mathrm{H}_{2} \mathrm{O}_{2}$ was used as positive control.

\subsection{RNA Extraction and Microarray Analysis}

$5 \times 10^{5}$ cells $/ \mathrm{mL}$ THP- 1 cells were treated with $50 \mu \mathrm{g} / \mathrm{mL}$ of $5 \mathrm{~nm}$ PtNPs for $6 \mathrm{~h}$. After the incubation time, the cells were washed twice and the total RNA was extracted with the RNeasy Plus Mini kit (Qiagen, Hilden, Geramny) following the manufacturer's instructions. The transcriptional profile of THP-1 cells was analyzed by Affymetrix genechip Clariom S Human (provided by Cogentech S.c.a.r.l., Milano, Italy). The results were analyzed by Partek Genomics Suite Software (St. Louis, MO, USA).

\subsection{Statistical Analysis}

All the experiments were performed in triplicate, at least in three independent assays. Statistically significant differences were determined by one-way or two-way Analysis of Variance (ANOVA) analysis followed by Bonferroni's or Tukey's post hoc test. A $p$ value of $<0.05$ was considered significant.

\section{Results}

\subsection{Cytocompatibility of PtNPs with THP-1 Monocytes}

5 and $20 \mathrm{~nm}$ citrate coated-PtNPs have been synthesized as previously reported [9] and characterized by Transmission Electron Microscopy (TEM) analysis (Figure S1A,B). The two sets of PtNPs had low polydispersity and quasi-spherical shape with pronounced external roughness (flower-like appearance), highly increasing their catalytic surfaces. The potential cytotoxicity of PtNPs, has been evaluated by Annexin V/PI and WST-8 assays performed on NP-treated THP-1 cells. 5 and $20 \mathrm{~nm}$ PtNPs did not induce significant necrotic or apoptotic cell death (Figure 1A-C), neither decrease THP-1 metabolism up to $100 \mu \mathrm{g} / \mathrm{mL}$ within $24 \mathrm{~h}$ (Figure 1D).

\subsection{THP-1 Monocyte Internalization of PtNPs}

The administration of PtNPs to THP-1 monocytes cultured in complete RPMI medium resulted in cell internalization of the NPs, as demonstrated by TEM (Figure 2A,B). High magnification intracellular TEM images highlight the endosomal localization of the particles and the higher amount of $5 \mathrm{~nm}$ PtNPs in the subcellular compartment compared to the $20 \mathrm{~nm}$. Experimental data show that maximal internalization of NPs is reached after $6 \mathrm{~h}$, as confirmed by increased light side scattering in flow cytometry (Figure 2C) and by elemental analysis using Inductively Coupled Plasma Atomic Emission Spectrometer (ICP-AES) (Figure S2). The slight decrease after $24 \mathrm{~h}$ could be possibly due to exocytosis mechanisms for endocytosed NPs [20]. We did not analyze further time points in our experiments since we studied the consequences of acute administration of PtNPs to THP- 1 cells, which complete their cell cycle after one day in culture and double in 35-50 $\mathrm{h} \mathrm{[21].}$

A

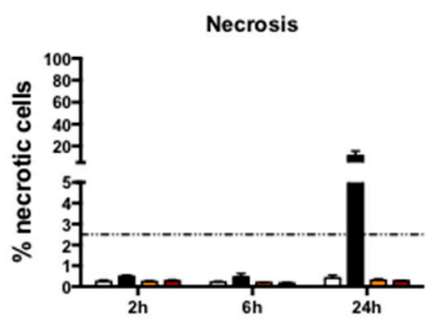

B

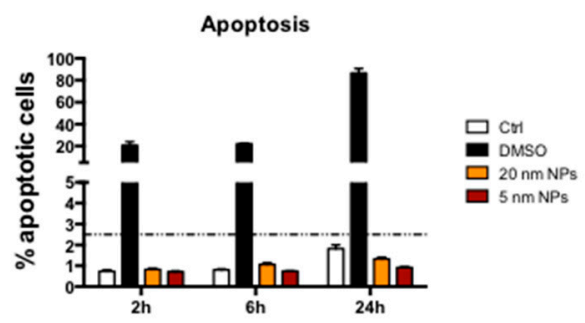

Figure 1. Cont. 
C

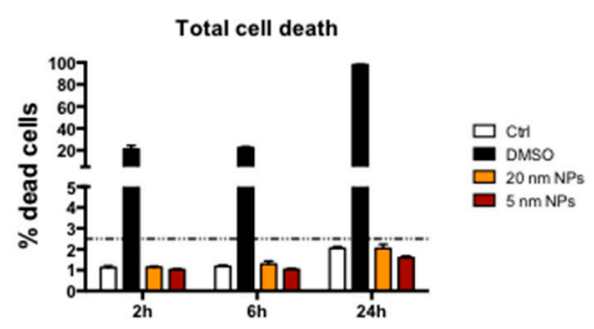

D

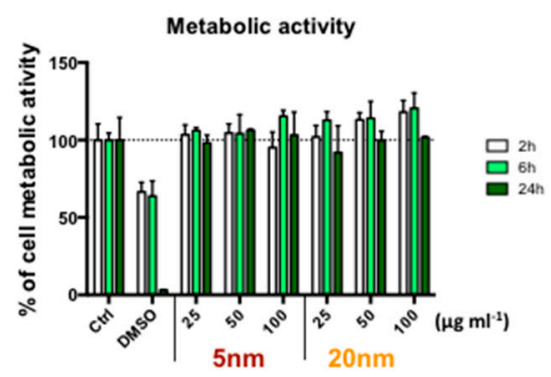

Figure 1. Cell viability. (A-C) Viability of THP-1 cells after 2, 6 and $24 \mathrm{~h}$ exposure to $50 \mu \mathrm{g} / \mathrm{mL}$ PtNPs. Control columns represent untreated cells. Necrotic, apoptotic and total dead cells were evaluated by flow cytometry using the Annexin V/PI assay; (D) Cell metabolic activity of THP-1 cells after 2, 6 and $24 \mathrm{~h}$ exposure to increasing doses of PtNPs evaluated by WST-8 assay. 10\% DMSO was used as positive control in all the experiments. Data are expressed in percentage relative to untreated control cells (empty columns).

A

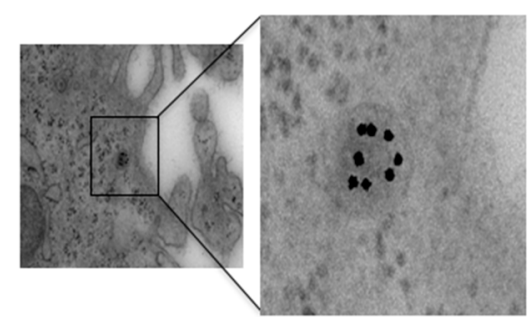

B

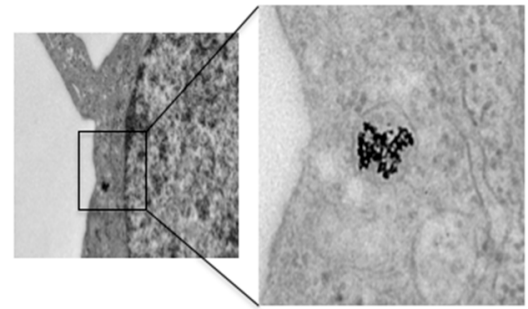

C

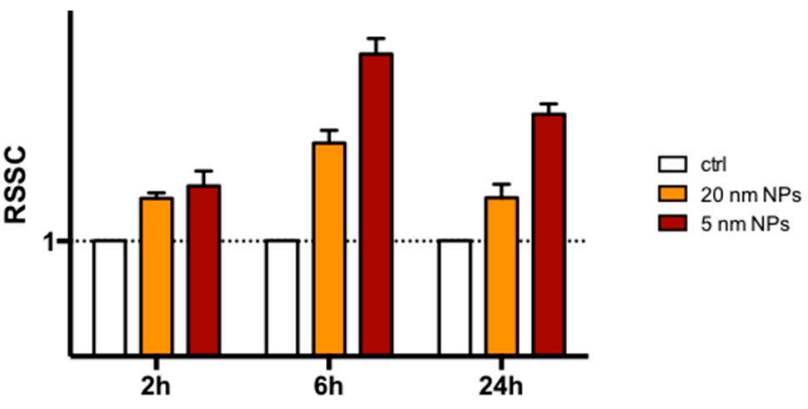

Figure 2. Cellular uptake and intracellular localization of PtNPs. High magnification TEM images of internalized $20 \mathrm{~nm}$ (A) and $5 \mathrm{~nm}$ (B) $50 \mu \mathrm{g} / \mathrm{mL}$ PtNPs in THP-1 cells; (C) Time variation of Side Scatter in THP-1 cells treated with $50 \mu \mathrm{g} / \mathrm{mL}$ PtNPs evaluated by flow cytometry. Data are normalized to untreated control (empty columns).

\subsection{Immune Receptor Expression in the Presence of PtNPs}

Modulation of immune receptor expression on the cell surface is an indication of possible membrane alteration or inappropriate response to intercellular communication. As PtNPs interact with monocyte membranes to proceed with their internalization, we evaluated by flow cytometry (Figure 3) the expression of the LPS co-receptor CD14 and the CD11b, whose up-regulation in different leukocytes is considered a marker of innate immune response [22]. We also analyzed two inflammatory chemokine receptors, namely CCR2 and CCR5, usually driving monocyte recruitment to the sites of inflammation [23]. The presence of 5 or $20 \mathrm{~nm}$ citrate-PtNPs for $24 \mathrm{~h}$ did not induce any significant 
variation in the receptor expression on the cell surface, suggesting low impact of PtNPs on membrane receptor presentation.

A
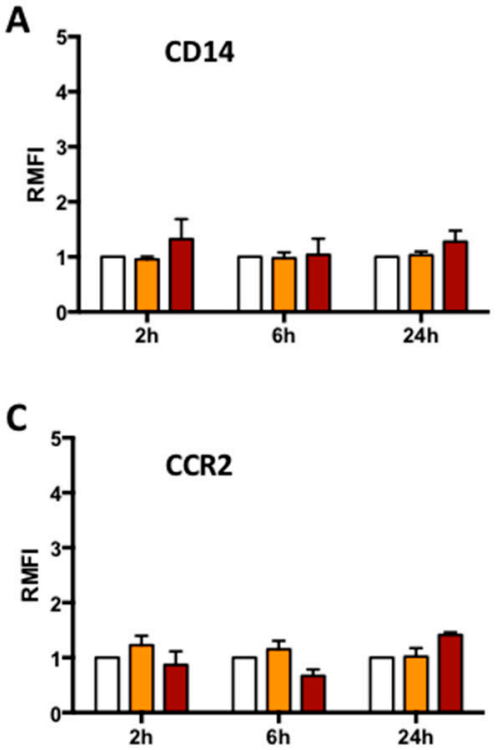

B

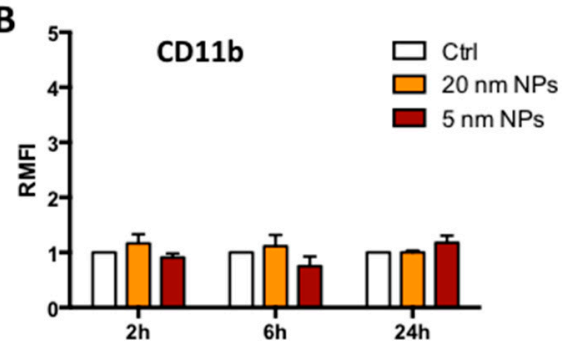

D

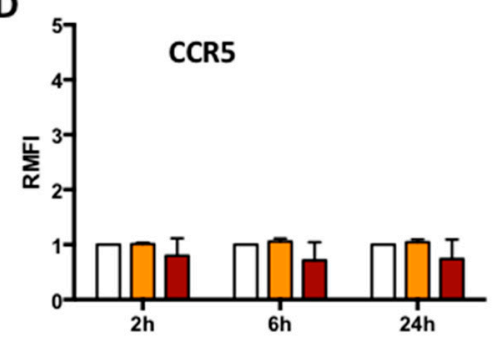

Figure 3. THP-1 receptor expression. Time dependent relative median fluorescence intensity (RMFI) evaluated by flow cytometry of CD14, CD11b, CCR2 and CCR5 after $50 \mu \mathrm{g} / \mathrm{mL}$ Pt-NP treatment of THP-1 cell. Control (Ctrl, empty columns) represents untreated cells.

\subsection{Cytokine Expression in the Presence of PTNPs}

Although we did not find signs of toxicity in NP-treated THP-1 monocytes, we investigated whether the presence of PtNPs could affect other cellular mechanisms involved in the immune response. Since monocytes coordinate immunity by the release of cytokines as mediators of inter-cellular communication, we treated THP-1 with $50 \mu \mathrm{g} / \mathrm{mL}$ NPs for $6 \mathrm{~h}$, previously demonstrated as the highest time point of particle internalization curve in our cell model (Figure 2), and cytokine levels measured $24 \mathrm{~h}$ after washing. The extracellular release of IL-1 $\beta$, IL-8, MCP-1, MIP-1 $\beta$, RANTES and TNF- $\alpha$ by PtNPs-treated monocytes was not different from untreated cells by both the NPs of different size (Figure 4). To confirm the normal production of cytokines by THP-1 we used LPS stimulation as positive control (Figure S3). This result emphasizes the immune-compatibility of citrate-coated PtNPs with THP-1 in vitro and their unstimulated release of cytokines.

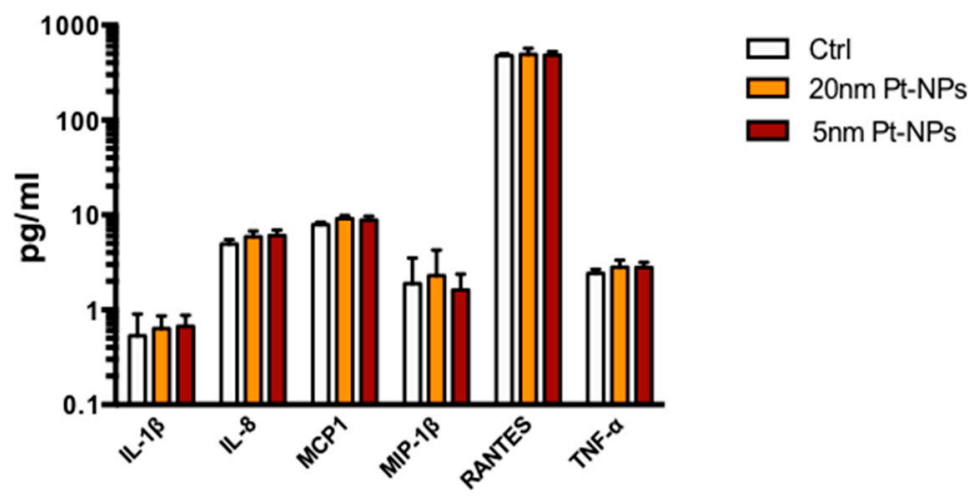

Figure 4. Cytokine release. Column graphs show IL-1 $\beta$, IL-8, MCP-1, MIP- $1 \beta$, RANTES and TNF- $\alpha$ levels released by THP-1 $24 \mathrm{~h}$ after treatment with $50 \mu \mathrm{g} / \mathrm{mL}$ PtNPs for $6 \mathrm{~h}$, measured by Bio-Plex MAGPIX Multiplex Reader. Control columns (Ctrl, empty columns) represent untreated cells. Results are expressed in $\mathrm{pg} / \mathrm{mL}$ in logarithmic scale. 


\subsection{Reactive Oxigen Species ( ROS) Scavenging Activity of PtNPs in THP-1 Monocytes}

Interestingly, we detected statistically significant decrease of ROS in THP-1 cells, measured by DCFH-DA assay in flow cytometry (Figure 5), in the presence of PtNPs vs. untreated cells. $5 \mathrm{~nm}$ PtNPs were more efficient in ROS scavenging activity ( $24 \%$ reduction vs. untreated) than $20 \mathrm{~nm}$ PtNPs (13\% reduction vs. untreated). The higher surface area/mass of the $5 \mathrm{~nm}$ NPs and their increased internalization (Figure 2B,C) into the cells might have amplified their efficiency. This result would be in agreement with the improved catalytic reaction by smaller NPs shown by Guarnieri and colleagues with $2.5 \mathrm{~nm}$ PtNP [24]. We demonstrated this effect for the first time in monocytes and confirmed what previously observed in other cell types by our group [9,24], and others [17].

\section{DCFH-DA}

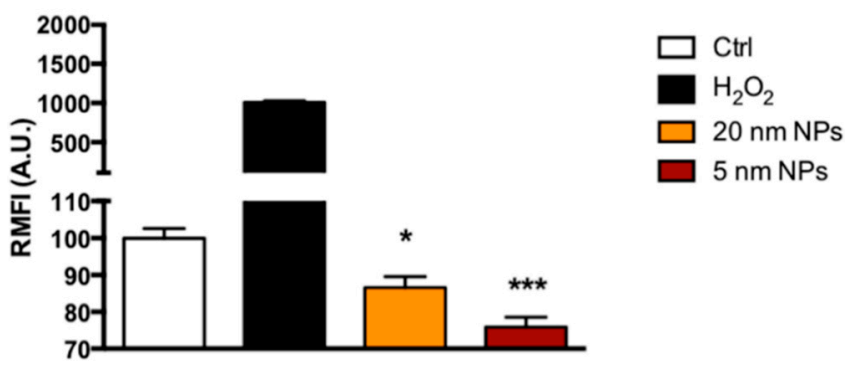

Figure 5. Antioxidant activity. ROS levels in THP-1 cells after $6 \mathrm{~h}$ exposure to $50 \mu \mathrm{g} / \mathrm{mL}$ PtNPs evaluated by the DCFH-DA assay in flow cytometry. Control (empty column) represents untreated cells. $1 \mathrm{mM} \mathrm{H}_{2} \mathrm{O}_{2}$ was used as positive control $\left({ }^{*} p<0.05\right.$, $\left.{ }^{* * *} p<0.001\right)$.

\subsection{Gene Transcription in THP-1 Treated with PtNPs}

As consequence of the previous result, we decided to investigate gene transcription by RNA microarray technology in THP-1 treated with the $5 \mathrm{~nm}$ PtNPs, which have shown increased internalization (Figure 2B,C) and ROS reduction (Figure 5). Most of the probed genes showed unaltered transcription (Figure $\mathrm{S} 4 \mathrm{~A}$ ), in reasonable agreement with the unaffected cell viability (Figure 1) physiological membrane protein expression (Figure 3) and basal cytokine release (Figure 4). However, among the 20,893 transcripts analyzed with the Affymetrix Human Clariom S array, we identified a group of 60 genes significantly down or up-regulated in the presence of PtNPs (Figure 6 and Figure S4B). Surprisingly, some of the downregulated genes have been related to pathogen dependent inflammatory pathways in lymphatic endothelial cells through caspase-1 (i.e., tlr1 [25], birc3 [26], serpinb9 [27]), somatostatin receptor expression in pulmonary tissues (sstr4 [28]), production of complement components (c3 [29]), neutrophil inflammatory response (aqp9 [30]) and leukemia progression (ephb4 [31]). The PtNP-induced upregulation of vstm1 and asap1 genes involves pathways regulating leukemia cell differentiation [32] and maturation [33]. The PtNP-treatment dependent gene upregulation of $\mathrm{mt} 2 \mathrm{a}$, which is coding for a methallothionein involved in the oxidative stress pathways and LPS induced inflammatory response in mice [34], highlights possible modification of innate immune response by PtNPs. The observed Pt-dependent modification of the transcription of other genes is difficult to relate to known cytokine pathways, since the specific function of their translated proteins is still not, or poorly, known in monocytes with a few indications in other tissues (e.g., sox5 [35], znf512 [36], efcab7 [37], thada [38], kndc1 [39]), albeit a role in innate immune response cannot be excluded.

Gene transcription results indicate feasible interaction of PtNPs with the innate response. However, no significant differences have been observed in resting THP-1 presenting PtNPs in their intracellular compartments (Figures 1-4). We previously demonstrated that PtNPs do not affect THP-1 growth and differentiation from monocytes to macrophages [40], restricting the importance of the downregulated genes belonging to these pathways in PtNP-treated monocytes [25-33]. 


\begin{tabular}{|c|c|c|}
\hline \multicolumn{3}{|c|}{ Cluster I (Down-regulation) } \\
\hline Gene Symbol & p value & Fold \\
\hline DHDH & 0.00680682 & -235.383 \\
\hline TMEM249 & 0.00125443 & -164.092 \\
\hline KRT10 & 0.00584153 & -183.224 \\
\hline SERPINB9 & 0.0127229 & -187.252 \\
\hline CHRNA2 & 0.0176239 & -198.697 \\
\hline DENND3 & 0.0177494 & -259.012 \\
\hline LRRC49 & 0.0382992 & -217.342 \\
\hline AQP9 & 0.0158562 & -199.371 \\
\hline C3 & 0.0205399 & $\begin{array}{l}-23.458 \\
\end{array}$ \\
\hline ARHGEF2 & 0.0317637 & -222.184 \\
\hline MS4A5 & 0.0407821 & -23.233 \\
\hline S100A3 & 0.0416953 & -225.937 \\
\hline A3GALT2 & 0.0375073 & -221.337 \\
\hline TLR1 & 0.0467382 & -286.595 \\
\hline BIRC3 & 0.0233418 & -204.706 \\
\hline AKAP6 & 0.0171676 & -241.813 \\
\hline MUC7 & 0.0119723 & -192.331 \\
\hline EPHB4 & 0.0452845 & -339.636 \\
\hline B3GAT1 & 0.0125254 & -186.891 \\
\hline PSG3 & 0.0143791 & -285.559 \\
\hline MC4R & 0.025562 & -26.033 \\
\hline SSTR4 & 0.0438795 & -265.089 \\
\hline СCT8L2 & 0.0285055 & -218.534 \\
\hline KNDC1 & 0.0369843 & -223.923 \\
\hline SSX8 & 0.0311138 & -21.814 \\
\hline SEBOX & 0.00546927 & -176.664 \\
\hline KIAA1462 & 0.00975295 & -18.494 \\
\hline OLIG2 & 0.00538781 & -172.017 \\
\hline NPNT & 0.00261383 & -168.666 \\
\hline MLXIP & 0.0443226 & -256.843 \\
\hline MICALCL & 0.0446203 & -282.846 \\
\hline
\end{tabular}

\begin{tabular}{|c|c|c|}
\hline \multicolumn{3}{|c|}{ Cluster II (Up-regulation) } \\
\hline Gene Symbol & p value & Fold \\
\hline EXOC3L4 & 0.0424156 & 104.207 \\
\hline BMP15 & 0.0426733 & 103.871 \\
\hline FHDC1 & 0.0418248 & 103.772 \\
\hline RBMY1J & 0.0350732 & 107.949 \\
\hline PACRG & 0.0325546 & 110.587 \\
\hline GEMIN2 & 0.0222288 & 117.022 \\
\hline TCF4 & 0.0226088 & 117.411 \\
\hline MAFTRR & 0.0253553 & 116.995 \\
\hline ABCA12 & 0.0307612 & 111.661 \\
\hline FMN1 & 0.0260612 & 115.907 \\
\hline THADA & 0.012653 & 141.745 \\
\hline ETNPPL & 0.0162528 & 1.221 \\
\hline ARSH & 0.00390911 & 14.735 \\
\hline DUSP28 & 0.0066659 & 133.464 \\
\hline HIP1R & 0.0106508 & 125.877 \\
\hline ZNF512 & 0.00937282 & 132.243 \\
\hline CCDC15 & 0.0145189 & 121.932 \\
\hline VSTM1 & 0.00305575 & 14.123 \\
\hline MT2A & 0.00799217 & 140.424 \\
\hline USP17L13 & 0.00951619 & 138.537 \\
\hline ASAP1 & 0.00489079 & 149.249 \\
\hline SoX5 & 0.00271791 & 146.437 \\
\hline RFPL4B & 0.0371449 & 107.384 \\
\hline OR2B3 & 0.0355683 & 107.716 \\
\hline ADGRG6 & 0.0247615 & 115.322 \\
\hline EFCAB7 & 0.00939086 & 139.712 \\
\hline ABI3BP & 0.0293028 & 113.338 \\
\hline C12orf60 & 0.0165129 & 131.612 \\
\hline COL25A1 & 0.0191849 & 126.531 \\
\hline
\end{tabular}

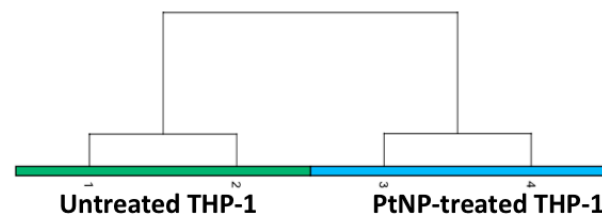

DHDH

TMEM249

KRT10
SERPINB9

CHRNA2

DENND3

LRRC49

AQP9
C3

ARHGEF2

MSAAS

S100A3

TLR1

TLR1

AKAP6

AKAP6
MUC7
EPHB4

B3GAT1

PSG3

MCAR

SSTR4

CCT8L2

KNDC1

SSX8
SEBOX

SEBOX
KIAA 1462

oLIG2

NPNT

MLIP

MICALCL

EXOC3L4
BMP15

FHDC1

RBMY1J
PACRG

PACRG
GEMIN2

TCF4

MAFTRR
ABCA12

FMN1

THADA

ETNPPL

ARSH

DUSP28
HIP1R

ZNF512

CCDC15

vSTM1

MT2A

USP17L13

ASAP1

sox5

RFPLAB
OR2B3

ADGRG6

EFCAB7

AB:38P

colv54

\section{Untreated THP-1 \\ PtNP-treated THP-1}
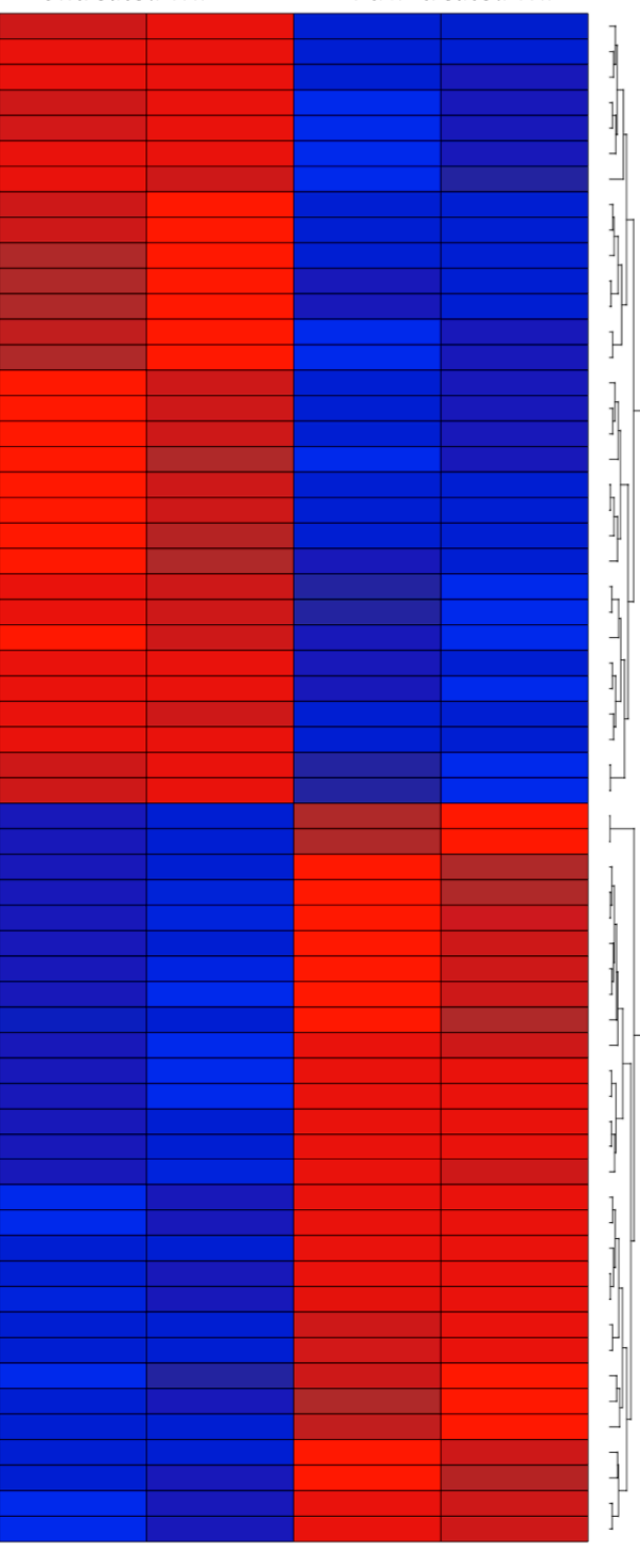

Figure 6. Gene expression-Hierarchical gene clustering. Gene transcription after $6 \mathrm{~h} 50 \mu \mathrm{g} / \mathrm{mL} 5 \mathrm{~nm}$ PtNPs treatment evaluated by microarray analysis. The heat map shows significant changes in a group of selected genes due to PtNPs exposure in THP-1 cells. Two clusters were detected, one due to down-regulation of the genes (blue) and other due to up-regulation of the genes (red) in NP-treated vs. $\mathrm{NP}$-untreated cells. Fold change and $p$-value of the genes in the clusters are given on the left. 


\subsection{Cytokine Expression in PtNP-Treated THP-1 after LPS Stimulation}

Gene transcription analysis do not exclude potential incorrect regulation of immune response to pathogenic stimulation in PtNPs-treated monocytes. Since the altered transcription of some genes, like tlr1, c3 and mt2a, is involved in LPS pathways in other cell types, we tested inflammatory cytokine release in LPS-activated THP-1 monocytes $24 \mathrm{~h}$ after the administration of $50 \mu \mathrm{g} / \mathrm{mL}$ PtNPs for $6 \mathrm{~h}$. As shown in Figure 7, no differences between NP-treated and untreated monocytes was detected.

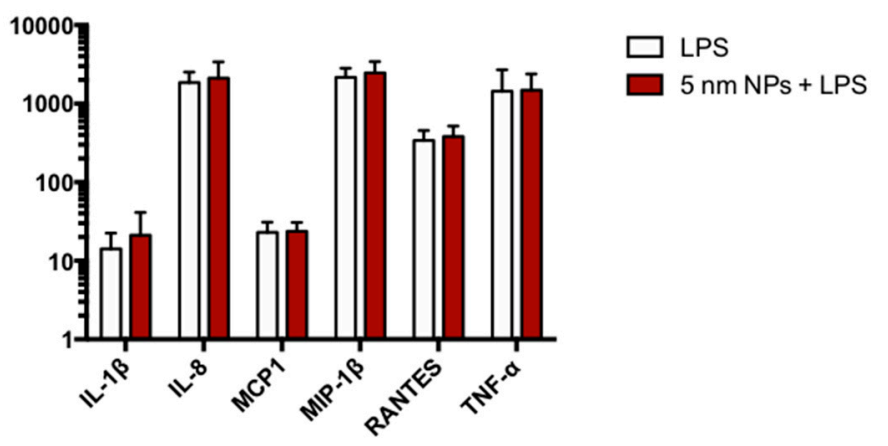

Figure 7. Cytokine release after LPS exposure. Column graphs show IL-1 $\beta$, IL-8, MCP-1, MIP-1 $\beta$, RANTES and TNF- $\alpha$ levels released by THP-1 after LPS exposure. The cells were treated for $6 \mathrm{~h}$ with $50 \mu \mathrm{g} / \mathrm{mL} 5 \mathrm{~nm}$ PtNPs, then washed and exposed to $100 \mathrm{ng} / \mathrm{mL}$ LPS for $24 \mathrm{~h}$. LPS columns (empty columns) represent untreated THP-1 cells stimulated with LPS.

\section{Discussion}

The PtNPs have already been demonstrated as ROS scavengers in cell lines and primary cells with pathological oxidative stress conditions [1,9] suggesting a potential role as synthetic nanoparticle-based enzymes ("nanozymes").

In the present manuscript, we have shown the highly monodispersed citrate-coated PtNPs (Figure S1) are not toxic (Figure 1) and can be internalized by human THP-1 monocytes (Figure 2). The good degree of cytocompatibility up to $100 \mu \mathrm{g} / \mathrm{mL}$ (Figure 1) is supported by our observation that PtNP-treated cells normally express immune receptors like CD14, CD11b, CCR2 and CCR5 indicating that their synthesis and the intracellular trafficking to the plasma membrane is not altered by the presence of PtNPs (Figure 3). As well, the basal release of inflammatory cytokines by resting THP-1 cell line is also not significantly modulated after NP treatment (Figure 4). Cytokine release experiments have been performed to detect the specific role of up-taken particles at the maximum time point of internalization, as indicated by TEM, flow cytometry (Figure 2) and ICP-AES (Figure S2). PtNPs in the extracellular medium can bind proteins, including cytokines, and underestimate their actual amount in the tested supernatants (data not shown).

Although toxicity and immune-responses of monocytes seems not compromised by the presence of PtNPs, we demonstrated an anti-oxidant activity by ROS reduction in the same cells (Figure 5). PtNP interference with fluorescent probes could raise some concerns, as shown for AuNPs and AgNPs [41]. Actually, plasmon resonance of platinum is in the UV region. Its visible spectrum does not have absorbance at 488 wavelength like $\mathrm{Au}$ and $\mathrm{Ag}$. The absence of direct interference with DCFH within cells has previously been demonstrated by our group in HeLa cells [9]. In this paper are shown no differences between PtNPs loaded cells and controls. It is important to be mentioned that in THP-1 the basal ROS level is higher than in HeLa cells, in which the decrease of ROS by $5 \mathrm{~nm}$ PtNPs can be detected only after $\mathrm{H}_{2} \mathrm{O}_{2}$ treatment. Indeed, the platinum catalytic efficiency is related to the surface/volume ratio as demonstrated by the increased activity of $2.5 \mathrm{~nm}$ PtNPs, which are able to reduce the basal ROS in the same cell line [24].

Genetic analysis by RNA microarray technology revealed PtNPs-induced statistically significant alteration of only 60 genes, some of them potentially involved in inflammatory pathways (Figure 6). 
It is worth to mention that most of the genes are normally transcribed in PtNP-treated THP-1 and perform regular physiological activities, as demonstrated by their viability, the expression of membrane receptors and cytokine production. Anyway, the down- or up-regulation of all the 60 RNA transcripts shown in Figure 6 renders quite difficult the precise role of the PtNPs in the several cell mechanisms. We focused our attention on the PtNP-dependent modulation of trl1 (Toll-Like-Receptor 1), c3 (Complement component 3), birc3 (baculoviral IAP repeat containing 3), sstr4 (Somatostatin receptor 4), serpinb9 (serpin family B member 9), and mt2a (metallothionein 2a) genes which have been shown to participate some inflammatory responses in other cell types following pathogenic stimuli like LPS [25-29,34]. So, we activated monocytes with LPS either in the presence or absence of PtNPs and measured the cytokine release. Our data do not show differences in the LPS-induced increase of IL-1 $\beta$, IL-8, MCP1, MIP-1 $\beta$, RANTES and TNF- $\alpha$ (Figure 7) between PtNP-treated and control THP-1 monocytes. Intriguingly, Rehman and colleagues [17] observed an anti-inflammatory effect of pectin-coated $2.5 \mathrm{~nm}$ PtNPs in LPS-induced inflammatory pathways using RAW264.7 murine macrophages. These results underline how slightly different PtNPs and the differentiation state of the monocyte/macrophage lineage may play an important role in the detected immune responses $[17,40]$. The complex signaling that regulate immunity could be also coordinated by genes with multiple functions. In the present study, the transcription of other genes involved in cell maturation and leukemia progression, such as ephb4, aqp9, asap1, vstm1 was also altered by PtNPs [30-33]. Nevertheless, we have previously demonstrated that citrate-coated PtNPs do not induce major effects in the differentiation process of THP-1 macrophages [40]. However, a more complex cascade-like mechanism cannot be excluded. Further research will be required to understand if the blockade of just one, or a few, of these genes could subsequently impair the transcription of other genes involved in immune mechanisms.

\section{Conclusions}

We have shown that citrate-coated PtNPs are not cytotoxic and immune-compatible with THP-1 monocytes. We measured PtNP ROS scavenging activity, likely contributing to the observed modulation of 60 genes. Finally, we demonstrated that PtNPs do not affect LPS-induced inflammatory cytokine upregulation and excluding the role of modulated genes in this phenomenon.

Supplementary Materials: The following are available online at http:/ /www.mdpi.com/2079-4991/8/6/392/s1, Figure S1: TEM images of PtNPs of $20 \mathrm{~nm}$ (A) and $5 \mathrm{~nm}$ (B) diameter with relative NPs size distribution analysis. Figure S2: Representative quantification of internalized PtNPs/cell by ICP-AES. The control column represents untreated cells. Figure S3: Cytokines release after LPS $100 \mathrm{ng} / \mathrm{ml}$ used as positive control. Figure S4: Scatter plot of untreated vs PtNPs treated THP-1 cells (A) and volcano plot of the 60 modulated genes (B).

Author Contributions: F.G. conceived, designed and performed most of the experiments and wrote the paper. M.M. synthesized and characterized platinum nanoparticles. P.P.P. contributed to the analysis and revised the paper. G.B. conceived the study, wrote and edited the paper. All the authors were involved in the data analysis and discussed the results.

Acknowledgments: The authors wish to thank the Microarray Unit of Cogentech for processing of microarrays and data analysis, Tiziano Catelani technical assistance with TEM.

Conflicts of Interest: The authors report no conflicts of interest.

\section{References}

1. Pedone, D.; Moglianetti, M.; De Luca, E.; Bardi, G.; Pompa, P.P. Platinum nanoparticles in nanobiomedicine. Chem. Soc. Rev. 2017, 46, 4951-4975. [CrossRef] [PubMed]

2. Karakoti, A.; Singh, S.; Dowding, J.M.; Seal, S.; Self, W.T. Redox-active radical scavenging nanomaterials. Chem. Soc. Rev. 2010, 39, 4422. [CrossRef] [PubMed]

3. Siddiqi, K.S.; Husen, A. Green Synthesis, Characterization and Uses of Palladium/Platinum Nanoparticles. Nanoscale Res. Lett. 2016, 11, 482. [CrossRef] [PubMed] 
4. Elder, A.; Yang, H.; Gwiazda, R.; Teng, X.; Thurston, S.; He, H.; Oberdörster, G. Testing Nanomaterials of Unknown Toxicity: An Example Based on Platinum Nanoparticles of Different Shapes. Adv. Mater. 2007, 19, 3124-3129. [CrossRef]

5. Hamasaki, T.; Kashiwagi, T.; Imada, T.; Nakamichi, N.; Aramaki, S.; Toh, K.; Morisawa, S.; Shimakoshi, H.; Hisaeda, Y.; Shirahata, S. Kinetic Analysis of Superoxide Anion Radical-Scavenging and Hydroxyl Radical-Scavenging Activities of Platinum Nanoparticles. Langmuir 2008, 24, 7354-7364. [CrossRef] [PubMed]

6. Horie, M.; Kato, H.; Endoh, S.; Fujita, K.; Nishio, K.; Komaba, L.K.; Fukui, H.; Nakamura, A.; Miyauchi, A.; Nakazato, T.; et al. Evaluation of cellular influences of platinum nanoparticles by stable medium dispersion. Metallomics 2011, 3, 1244. [CrossRef] [PubMed]

7. Hosaka, H.; Haruki, R.; Yamada, K.; Böttcher, C.; Komatsu, T. Hemoglobin-Albumin Cluster Incorporating a Pt Nanoparticle: Artificial O2 Carrier with Antioxidant Activities. PLoS ONE 2014, 9, e110541. [CrossRef] [PubMed]

8. Kim, W.-K.; Kim, J.-C.; Park, H.-J.; Sul, O.-J.; Lee, M.-H.; Kim, J.-S.; Choi, H.-S. Platinum nanoparticles reduce ovariectomy-induced bone loss by decreasing osteoclastogenesis. Exp. Mol. Med. 2012, 44, 432-439. [CrossRef] [PubMed]

9. Moglianetti, M.; De Luca, E.; Pedone, D.; Marotta, R.; Catelani, T.; Sartori, B.; Amenitsch, H.; Retta, S.F.; Pompa, P.P. Platinum nanozymes recover cellular ROS homeostasis in an oxidative stress-mediated disease model. Nanoscale 2016, 8, 3739-3752. [CrossRef] [PubMed]

10. Nomura, M.; Yoshimura, Y.; Kikuiri, T.; Hasegawa, T.; Taniguchi, Y.; Deyama, Y.; Koshiro, K.; Sano, H.; Suzuki, K.; Inoue, N. Platinum nanoparticles suppress osteoclastogenesis through scavenging of reactive oxygen species produced in RAW264.7 cells. J. Pharmacol. Sci. 2011, 117, 243-252. [CrossRef] [PubMed]

11. Shibuya, S.; Ozawa, Y.; Watanabe, K.; Izuo, N.; Toda, T.; Yokote, K.; Shimizu, T. Palladium and Platinum Nanoparticles Attenuate Aging-Like Skin Atrophy via Antioxidant Activity in Mice. PLoS ONE 2014, 9, e109288. [CrossRef] [PubMed]

12. Shiny, P.J.; Mukherjee, A.; Chandrasekaran, N. Haemocompatibility assessment of synthesised platinum nanoparticles and its implication in biology. Bioprocess Biosyst. Eng. 2014, 37, 991-997. [CrossRef] [PubMed]

13. Yoshihisa, Y.; Zhao, Q.-L.; Hassan, M.A.; Wei, Z.-L.; Furuichi, M.; Miyamoto, Y.; Kondo, T.; Shimizu, T. SOD/catalase mimetic platinum nanoparticles inhibit heat-induced apoptosis in human lymphoma U937 and HH cells. Free Radic. Res. 2011, 45, 326-335. [CrossRef] [PubMed]

14. Nejdl, L.; Kudr, J.; Moulick, A.; Hegerova, D.; Ruttkay-Nedecky, B.; Gumulec, J.; Cihalova, K.; Smerkova, K.; Dostalova, S.; Krizkova, S.; et al. Platinum nanoparticles induce damage to DNA and inhibit DNA replication. PLoS ONE 2017, 12, e0180798. [CrossRef] [PubMed]

15. Albanese, A.; Tang, P.S.; Chan, W.C.W. The Effect of Nanoparticle Size, Shape, and Surface Chemistry on Biological Systems. Annu. Rev. Biomed. Eng. 2012, 14, 1-16. [CrossRef] [PubMed]

16. Crist, R.M.; Grossman, J.H.; Patri, A.K.; Stern, S.T.; Dobrovolskaia, M.A.; Adiseshaiah, P.P.; Clogston, J.D.; McNeil, S.E. Common pitfalls in nanotechnology: lessons learned from NCI's Nanotechnology Characterization Laboratory. Integr. Biol. (Camb). 2013, 5, 66-73. [CrossRef] [PubMed]

17. Rehman, M.U.; Yoshihisa, Y.; Miyamoto, Y.; Shimizu, T. The anti-inflammatory effects of platinum nanoparticles on the lipopolysaccharide-induced inflammatory response in RAW 264.7 macrophages. Inflamm. Res. 2012, 61, 1177-1185. [CrossRef] [PubMed]

18. Abbas, A.K.; Lichtman, A.H.; Pillai, S. Cellular and Molecular Immunology; Elsevier: New York, NY, USA, 2015; ISBN 9780323316149.

19. Ingersoll, M.A.; Platt, A.M.; Potteaux, S.; Randolph, G.J. Monocyte trafficking in acute and chronic inflammation. Trends Immunol. 2011, 32, 470-477. [CrossRef] [PubMed]

20. Fröhlich, E. Cellular elimination of nanoparticles. Environ. Toxicol. Pharmacol. 2016, 46, 90-94. [CrossRef] [PubMed]

21. Chanput, W.; Mes, J.J.; Wichers, H.J. THP-1 cell line: An in vitro cell model for immune modulation approach. Int. Immunopharmacol. 2014, 23, 37-45. [CrossRef] [PubMed]

22. Gorczyca, W.; Sun, Z.-Y.; Cronin, W.; Li, X.; Mau, S.; Tugulea, S. Immunophenotypic Pattern of Myeloid Populations by Flow Cytometry Analysis. Methods Cell Biol. 2011, 103, 221-266. [PubMed]

23. White, G.E.; Iqbal, A.J.; Greaves, D.R. CC Chemokine Receptors and Chronic Inflammation-Therapeutic Opportunities and Pharmacological Challenges. Pharmacol. Rev. 2013, 65, 47-89. [CrossRef] [PubMed] 
24. Guarnieri, D.; Melone, P.; Moglianetti, M.; Marotta, R.; Netti, P.A.; Pompa, P.P. Particle size affects the cytosolic delivery of membranotropic peptide-functionalized platinum nanozymes. Nanoscale 2017, 9, 11288-11296. [CrossRef] [PubMed]

25. Garrafa, E.; Imberti, L.; Tiberio, G.; Prandini, A.; Giulini, S.M.; Caimi, L. Heterogeneous expression of toll-like receptors in lymphatic endothelial cells derived from different tissues. Immunol. Cell Biol. 2011, 89, 475-481. [CrossRef] [PubMed]

26. Labbé, K.; McIntire, C.R.; Doiron, K.; Leblanc, P.M.; Saleh, M. Cellular Inhibitors of Apoptosis Proteins cIAP1 and cIAP2 Are Required for Efficient Caspase-1 Activation by the Inflammasome. Immunity 2011, 35, 897-907. [CrossRef] [PubMed]

27. Van der Burgh, R.; Meeldijk, J.; Jongeneel, L.; Frenkel, J.; Bovenschen, N.; van Gijn, M.; Boes, M. Reduced serpinB9-mediated caspase-1 inhibition can contribute to autoinflammatory disease. Oncotarget 2016, 7, 19265-19271. [CrossRef] [PubMed]

28. Varecza, Z.; Elekes, K.; László, T.; Perkecz, A.; Pintér, E.; Sándor, Z.; Szolcsányi, J.; Keszthelyi, D.; Szabó, Á.; Sándor, K.; Molnár, T.F.; Szántó, Z.; Pongrácz, J.E.; Helyes, Z. Expression of the Somatostatin Receptor Subtype 4 in Intact and Inflamed Pulmonary Tissues. J. Histochem. Cytochem. 2009, 57, 1127-1137. [CrossRef] [PubMed]

29. Lubbers, R.; van Essen, M.F.; van Kooten, C.; Trouw, L.A. Production of complement components by cells of the immune system. Clin. Exp. Immunol. 2017, 188, 183-194. [CrossRef] [PubMed]

30. Matsushima, A.; Ogura, H.; Koh, T.; Shimazu, T.; Sugimoto, H. Enhanced Expression of Aquaporin 9 in Activated Polymorphonuclear Leukocytes in Patients With Systemic Inflammatory Response Syndrome. Shock 2014, 42, 322-326. [CrossRef] [PubMed]

31. Zhou, X.; Xiaoli, L.; Xu, N.; Li, L.; Lu, Q.; Zhang, J.; Huang, B.; Du, Q. EphrinB2/EphB4 Interaction Promotes Myeloid Leukemia Cell Invasion through RhoA-Mediated Mechanism. Blood 2014, 124, 1018.

32. Xie, M.; Li, T.; Li, N.; Li, J.; Yao, Q.; Han, W.; Ruan, G. VSTM-v1, a potential myeloid differentiation antigen that is downregulated in bone marrow cells from myeloid leukemia patients. J. Hematol. Oncol. 2015, 8, 25. [CrossRef] [PubMed]

33. Curtis, J.; Luo, Y.; Zenner, H.L.; Cuchet-Lourenço, D.; Wu, C.; Lo, K.; Maes, M.; Alisaac, A.; Stebbings, E.; Liu, J.Z.; et al. Susceptibility to tuberculosis is associated with variants in the ASAP1 gene encoding a regulator of dendritic cell migration. Nat. Genet. 2015, 47, 523-527. [CrossRef] [PubMed]

34. Inoue, K.-I.; Takano, H.; Shimada, A.; Wada, E.; Yanagisawa, R.; Sakurai, M.; Satoh, M.; Yoshikawa, T. Role of metallothionein in coagulatory disturbance and systemic inflammation induced by lipopolysaccharide in mice. FASEB J. 2006, 20, 533-535. [CrossRef] [PubMed]

35. Lefebvre, V. The SoxD transcription factors-Sox5, Sox6, and Sox13-are key cell fate modulators. Int. J. Biochem. Cell Biol. 2010, 42, 429-432. [CrossRef] [PubMed]

36. Schmidtmann, E.; Anton, T.; Rombaut, P.; Herzog, F.; Leonhardt, H. Determination of local chromatin composition by CasID. Nucleus 2016, 7, 476-484. [CrossRef] [PubMed]

37. Pusapati, G.V.; Hughes, C.E.; Dorn, K.V.; Zhang, D.; Sugianto, P.; Aravind, L.; Rohatgi, R. EFCAB7 and IQCE Regulate Hedgehog Signaling by Tethering the EVC-EVC2 Complex to the Base of Primary Cilia. Dev. Cell 2014, 28, 483-496. [CrossRef] [PubMed]

38. Zhao, F.; Xu, Y.; Yang, K.; Liu, M.; Wei, D.; Zhang, Y.; Shi, X.; Yang, F.; Wang, X.; Liang, S.; et al. THADA gene polymorphism and prostate cancer risk: a meta-analysis. Oncol. Res. Treat. 2014, 37, 106-110. [CrossRef] [PubMed]

39. Zhang, C.; Zhen, Y.-Z.; Lin, Y.-J.; Liu, J.; Wei, J.; Xu, R.; Hu, G. KNDC1 knockdown protects human umbilical vein endothelial cells from senescence. Mol. Med. Rep. 2014, 10, 82-88. [CrossRef] [PubMed]

40. Gatto, F.; Cagliani, R.; Catelani, T.; Guarnieri, D.; Moglianetti, M.; Pompa, P.; Bardi, G. PMA-Induced THP-1 Macrophage Differentiation is Not Impaired by Citrate-Coated Platinum Nanoparticles. Nanomaterials 2017, 7, 332. [CrossRef] [PubMed]

41. Singha, S.; Kim, D.; Seo, H.; Cho, S.W.; Ahn, K.H. Fluorescence sensing systems for gold and silver species. Chem. Soc. Rev. Chem. Soc. Rev 2015, 44, 4367-4399. [CrossRef]

(C) 2018 by the authors. Licensee MDPI, Basel, Switzerland. This article is an open access article distributed under the terms and conditions of the Creative Commons Attribution (CC BY) license (http:/ / creativecommons.org/licenses/by/4.0/). 